\title{
O Arquivo Nacional na "Sala de Aula": fontes históricas na construção do conhecimento
}

\author{
The National Archive in the "Classroom": \\ Historical sources in the construction of knowledge
}

Marieta Pinheiro de Carvalho*

Vivian Cristina da Silva Zampa**

\section{Resumo}

$\mathrm{O}$ artigo tem como finalidade analisar a utilização de fontes históricas como um dos recursos pedagógicos das aulas de História, enfatizando o movimento que vem se desenvolvendo nas últimas décadas no Brasil de aproximação entre o chamado "saber histórico escolar" e as recomendações do Ministério da Educação para a Educação Básica. Faz-se um recorte no acervo relativo à história colonial custodiado pelo Arquivo Nacional no Rio de Janeiro, que possibilita o redimensionamento de questões tradicionalmente não aprofundadas e que, por vezes, desperta maior interesse discente. Ressalta-se, dessa forma, que a relação do ensino de História com a problematização é um dos maiores desafios da atualidade ao possibilitar, por exemplo, uma participação mais ativa e emancipadora dos alunos no processo de construção do conhecimento.

Palavras-chave: fontes históricas; ensino; período colonial; Arquivo Nacional (RJ).

\section{Abstract}

The article aims to analyze the use of historical sources as one of the pedagogical resources of History classes, emphasizing the movement that has been developing in the last decades in Brazil of approaching the so-called "school historical knowledge" and the institutional recommendations for Basic Education. In this sense, a cut is made from the collection related to colonial history in the Arquivo Nacional in Rio de Janeiro, which allows the resizing of issues that are traditionally undefined and which, at times, arouses a greater student interest. It should be emphasized that the relationship between History teaching and problemsolving is one of the greatest challenges of our time, making possible, for example, a more active and emancipatory participation of students in the process of knowledge construction.

Keywords: Historical sources; education; colonial period; Arquivo Nacional (RJ).

\footnotetext{
* Doutora em História Política, Universidade do Estado do Rio de Janeiro (Uerj). Professora do Programa de Pós-Graduação em História, Universidade Salgado de Oliveira (Universo). Niterói, RJ, Brasil.marietacarvalho@gmail.com

** Doutora em História Política, Universidade do Estado do Rio de Janeiro (Uerj). Professora do Instituto de Aplicação Fernando Rodrigues da Silveira (CAp/Uerj). Rio de Janeiro, RJ, Brasil. vivianzampa@hotmail.com
} 
As discussões acerca da formação e prática do professor de História ganharam destaque nos encontros e publicações dessa área nas últimas décadas, seja por influência de inovações historiográficas e debates empreendidos no país desde o fim da década de 1980, seja por trabalhos específicos da área, como os desenvolvidos por Jaime Pinsky (1988), Elza Nadai (1993), Circe Bittencourt (2005) e Thaís Nívia de Lima e Fonseca (2003), entre outros. A isso se acrescem, ainda, as transformações na política educacional advindas com a promulgação da Constituição Federal de 1988 e a implantação da Lei de Diretrizes e Bases da Educação, de 1996.

Ao analisar a trajetória do ensino de História no Brasil, Thaís Fonseca argumenta que, a partir do movimento de renovação historiográfica brasileiro influenciado pela chamada Nova História, a partir dos anos 1980, e da redemocratização do país, houve a tendência, entre professores, autores de livros didáticos e profissionais ligados à educação, de procurarem, de forma sistemática, "a sintonia entre o saber científico e o saber escolar" (Fonseca, 2003, p.66). Tendência ampliada na forma de discussões e produção de textos, com a criação de eventos na área, como o pioneiro "I Encontro de Professores e Pesquisadores em Ensino de História”, de 1993, e de espaços voltados ao ensino nos simpósios regionais e nacionais da Associação Nacional de História (Anpuh).

As reflexões produzidas desde então, de forma geral, partem do princípio de que o ensino de História constitui campo específico do conhecimento, que, por ser diferente da história acadêmica, requer problematização peculiar, embasada por questões teóricas e metodológicas próprias à área. Sobre esse aspecto, Flávia Eloisa Caimi destacou ser necessário atentar para o fato de que "os dois campos - escolar e acadêmico - são portadores de dinâmicas próprias, as quais se relacionam com inúmeras distâncias e dimensões, de acordo com as finalidades e especificidades de sua atuação" (Caimi, 2008, p.130).

$\mathrm{O}$ aprofundamento das pesquisas em torno do ensino de História, bem como de seu espaço nos cursos de licenciatura da área, nos programas de pós-graduação e em livros e periódicos científicos publicados nos últimos anos, contribuiu para a sua valorização enquanto objeto de pesquisa, indicando a possibilidade de configuração de novos problemas e abordagens, entre os quais os métodos e recursos que podem ser empregados para despertar, nos alunos, o interesse pelo fazer histórico. 
Ao longo deste artigo, temos por objetivo refletir sobre o uso de documentos como recurso pedagógico nas aulas de História. Inicialmente, realizaremos uma discussão sobre a sua importância e a maneira como ele está relacionado às propostas de ensino, às políticas públicas e aos Parâmetros Curriculares Nacionais (PCNs). Num segundo momento, com base no acervo relativo à história colonial depositado no Arquivo Nacional, no Rio de Janeiro, analisaremos as possibilidades propiciadas por tais fontes ao professor em sua prática docente. Essas fontes estão disponíveis online, no projeto "O Arquivo Nacional e a História Luso-Brasileira".

\section{O USO DE DOCUMENTOS NA PRÁTICA DOCENTE}

Os documentos tornam-se importantes como um investimento ao mesmo tempo afetivo e intelectual no processo de aprendizagem, mas seu uso será equivocado caso se pretenda que o aluno se transforme em um "pequeno historiador", uma vez que, para os historiadores, os documentos têm outra finalidade, que não pode ser confundida com a situação de ensino de História. (Bittencourt, 2005, p.328)

O alerta realizado por Bittencourt é fundamental para o início de uma reflexão sobre a importância do uso de documentos históricos em sala de aula. Trata-se de um instrumento pedagógico que possibilita aos alunos o contato com o "real". Além de tornar mais concreto o processo de ensino-aprendizagem, favorece o desenvolvimento intelectual dos alunos, permitindo ao docente sair do verbalismo que, na maioria das vezes, ainda hoje, infelizmente faz parte do cotidiano escolar. Entretanto, como salienta a autora, é preciso sensibilidade, por parte do professor, na utilização desse recurso, uma vez que os discentes não têm quaisquer tipos de pretensões historiográficas.

O emprego de fontes, na prática escolar, deve ter como foco maior "desenvolver uma autonomia intelectual capaz de propiciar análises críticas da sociedade em uma perspectiva temporal" (Bittencourt, 2005, p.328). Com isso, exige-se habilidade do professor, que deve buscar equilíbrio sobre uma linha tênue: ao utilizar tal recurso e trazer para os alunos as inovações no campo acadêmico, não pode acreditar que estará formando "possíveis historiadores". $\mathrm{O}$ uso de documentos, na prática docente, desse modo, deve servir como um recurso que vise "propiciar reflexões sobre a relação presente-passado e criar 
situações didáticas para que conheça e domine procedimentos de como interrogar obras humanas do seu tempo e de outras épocas" (Brasil, 1998, p.85).

Produzido em época específica, com objetivos muitas vezes distintos daquele para o qual mais tarde será aplicado, o documento só ganha uma perspectiva histórica a partir do momento em que é problematizado, e, para isso, é fundamental uma análise do contexto em que foi escrito. Como destacou Henri Moniot:

O saber histórico é produto de fontes, todas elas vindas do passado, e de uma crítica, vinda do historiador, um especialista que explora o seu conteúdo! ... Mas não é preciso advertir que o trabalho do historiador não pode estar limitado a isso ... O historiador diante dessa matéria-prima, das fontes, faz perguntas, coloca problemas. Mas é preciso inicialmente saber o que esta fonte dizia antes aos outros, como era usada para outra coisa, é preciso adquirir conhecimento sobre ela ... e a partir desses dados obtidos, talvez essa fonte possa fornecer e acrescentar novas ou algumas informações para a pesquisa. (Moniot apud Bittencourt, 2005, p.328-329)

Numa abordagem escolar, a utilização de fontes históricas assume perspectiva diferenciada, até porque os alunos desconhecem o contexto no qual o documento foi constituído. Desse modo, é preciso que o professor esteja atento para o "momento propício de introduzi-lo como material didático e à escolha dos tipos adequados ao nível e às condições de escolarização dos alunos" (Bittencourt, 2005, p.328).

As fontes históricas são o material que os historiadores utilizam em suas pesquisas, a partir de abordagens, métodos e técnicas específicos (Pinsky, 2005, p.7). Nas últimas décadas, sob a influência da historiografia dos Annales, sobretudo ligada à Nova História, o conceito de fontes históricas foi ampliado, passando a ser entendido, para além do documento escrito, como vestígios do passado, incluindo monumentos, mitos, fotografias e objetos, entre outros.

Fonte histórica, documento, registro, vestígio são todos termos correlatos para definir tudo aquilo produzido pela humanidade no tempo e no espaço; a herança material e imaterial deixada pelos antepassados que serve de base para a construção do conhecimento histórico. O termo mais clássico para conceituar a fonte histórica é documento. Palavra, no entanto, que, devido às concepções da escola 
metódica, ou positivista, está atrelada a uma gama de ideias preconcebidas, significando não apenas o registro escrito, mas principalmente o registro oficial. Vestígio é a palavra atualmente preferida pelos historiadores que defendem que a fonte histórica é mais do que o documento oficial: que os mitos, a fala, o cinema, a literatura, tudo isso, como produtos humanos, torna-se fonte para o conhecimento da história. (Silva; Silva, 2009, p.158)

Partindo dessa premissa, desenvolveu-se uma preocupação com a incorporação das inovações produzidas no campo acadêmico ao conteúdo ministrado pelo professor em sua sala de aula. O processo de renovação da historiografia brasileira, no final dos anos 1980 e início da década seguinte, também atingiu o ensino de História ministrado nas escolas. Como destacou Thaís Fonseca:

Tornou-se mais desejável, a partir de meados da década de 90, que os programas curriculares e os livros didáticos incorporassem as tendências da historiografia contemporânea, como foi o caso da história das mentalidades e da história do cotidiano, ainda hoje predominantes quando se fala em inovação no ensino de História. (Fonseca, T., 2003, p.66)

Essas mudanças foram positivamente incorporadas nos materiais produzidos após essa década, bem como na própria compreensão do papel do aluno em sala de aula. Nessa perspectiva, Carlos Mathias argumentou que "o ensino de história angariou a tarefa de capacitar o aluno a questionar sua própria historicidade e refletir sobre a natureza histórica do mundo, noutros termos, torná-lo crítico ... Apto a pensar a história e não apenas decorar nomes e datas, o aluno deveria, pois, defender suas ideias e, mais importante, deter a habilidade de modificá-las quando pertinente" (Mathias, 2011, p.47). O exercício da reflexão tinha de ser estimulado pelos docentes, como também deveria ser valorizado o conhecimento prévio do aluno, tornando-o sujeito do processo histórico.

Quanto à produção de materiais escolares, Fonseca evidencia que, em alguns livros escolares publicados depois de 1997, era possível perceber uma discussão mais ampla sobre a escravidão "mas ainda dedica[va]m pouco espaço à incorporação das abordagens historiográficas mais críticas, que apresentam 
o negro, escravo ou forro, como um sujeito que não é o tempo todo vítima ou coisa" (Fonseca, T., 2003, p.98).

A questão indicada por Fonseca aponta para determinadas permanências que, a despeito das inovações no campo historiográfico, ainda se fazem presentes nos livros didáticos, e que, por vezes, se tornam um meio da memória coletiva. De acordo com Halbwachs (1990), a memória coletiva é aquela que advém da construção de uma memória em comum de determinada sociedade, na qual estaria envolvida a conciliação entre ela e a memória individual, com vistas à construção de uma comunidade de pertencimento. Quando o livro didático passa a ser utilizado como o único recurso em sala de aula, ele se torna meio da memória coletiva, sendo portador de determinadas "verdades" que, em alguns casos, estão distantes de novas problemáticas, novas abordagens e novos objetos da História (Lindemeyer, 2013, p.3). Nesse caso, as representações da memória coletiva estão mais presentes no ambiente escolar do que as inovações historiográficas, "isso tanto em função de os estudantes estarem, obviamente, mergulhados nela", quanto pelo fato de "os professores, por razões diversas, igualmente, em boa parte, estarem mais suscetíveis a ela do que à pesquisa histórica e às novidades da historiografia" (Pereira; Seffner, 2008, p.121). Nessa perspectiva, presente em boa parte do cotidiano docente, trabalhar com documentos históricos em sala de aula pode ser uma forma de romper com determinadas barreiras da atualização do conhecimento.

Como afirmou Caimi, as políticas públicas educacionais recentes atentam para a necessidade de uma nova abordagem metodológica na utilização de fontes históricas: "Para além do caráter ilustrativo e comprobatório que o uso escolar de fontes assumiu nos manuais didáticos em épocas passadas, as atuais políticas definem um novo ideário, que imprime centralidade à tarefa de relacionar o estudo de fontes históricas à construção do conhecimento" (Caimi, 2008, p.147).

A autora ressalta que, num conjunto de 13 "situações didáticas" apresentadas nos PCNs dedicados aos anos finais do ensino fundamental, três referem-se a essa nova abordagem metodológica sobre o uso de fontes, estando tal perspectiva totalmente alinhada à historiografia recente.

Apresentando uma parte específica, intitulada "o trabalho com documentos", por meio da qual incentiva a sua utilização, os PCNs descrevem os documentos históricos como "as mais diversas obras humanas produzidas nos mais 
diferentes contextos sociais e com objetivos variados", compreendendo-os como "fundamentais no trabalho de produção do conhecimento histórico". Os Parâmetros atribuem ao professor o papel de mediação, de "conhecer e distinguir algumas abordagens e tratamentos dados às fontes por estudiosos da História", mas, ao mesmo tempo, "recriar, avaliar e reconstruir metodologias do saber histórico para situações de ensino e aprendizagem" (Brasil, 1998, p.83).

É o docente, em sua prática cotidiana, que saberá o momento adequado para trabalhar com os documentos, decidindo as intenções didáticas e a especificidade da temática histórica estudada. De igual maneira, é preciso que ele estabeleça "critérios de escolha" a partir de questionamentos que podem orientar a sua atividade:

O documento não fala por si mesmo, isto é, ele precisa ser interrogado a partir do problema estudado, construído na relação presente-passado;

Para interrogar o documento é preciso fazer a escolha de um método, isto é, escolher procedimentos que orientem na observação, na identificação de ideias, temas e contextos, na descrição do que foi identificado, na distinção de relações de oposição, associação e identidade entre as informações levantadas e na interpretação dos dados, considerando a relação presente-passado;

Os métodos mais adequados são aqueles que possibilitam extrair dos documentos informações de suas formas (materiais, gráficas e discursivas) e de seus conteúdos (mensagens, sentidos e significados) e que permitam compreendê-los no contexto de sua produção. (Brasil, 1998, p.86)

Três são as questões que se tornam evidentes nessa espécie de roteiro apresentado nos PCNs para orientar o professor no trabalho com documentos. A primeira delas parte do princípio de que é preciso construir, com os alunos, uma análise crítica do documento. A segunda, utilizá-lo como ferramenta importante que permita realizar conexões entre presente e passado, explorando-o para além das possibilidades que teriam no seu período de elaboração. E a terceira, a necessidade de contextualização, para que o aluno compreenda em que momento foi produzido.

Tais sugestões trazem à tona um ponto importante nas discussões sobre as renovações propiciadas após a década de 1990: o papel do aluno como 
elemento fundamental na construção do conhecimento. Professor e aluno são vistos como sujeitos da ação pedagógica, que se realiza de forma construtiva.

O uso de documentos, em sala de aula, cumpre, dessa maneira, a função de ajudar a construir o pensamento crítico, e de contribuir para tornar mais concretos conteúdos, por vezes, marcados pela abstração. Como argumentou Selva Fonseca em Didática e Prática de Ensino (2003), “a lógica fundante da produção do saber histórico é a explicitação do real”, tornar mais concreto o processo de ensino-aprendizagem. E somente a adoção de uma posição investigativa possibilita a construção do conhecimento. Em suas palavras, o professor deve realizar:

Uma busca permanente de superação do mero reprodutivismo livresco que ainda predomina nas aulas de História. O professor submisso ao reprodutivismo assume uma concepção de conhecimento como verdade absoluta e imutável. Ao contrário disso, assumir a proposição investigativa em sala de aula implica ousar e construir uma atitude reflexiva e questionadora diante do conhecimento historicamente produzido. (Fonseca, S., 2003, p.119)

Acreditamos que o projeto "Sala de Aula", que disponibiliza fontes documentais do Arquivo Nacional, no Rio de Janeiro, sobre a história colonial brasileira, é um recurso pedagógico relevante para auxiliar os professores de ensino fundamental e médio em suas aulas sobre o Brasil. Ao longo do próximo tópico, analisaremos o projeto, demonstrando como a utilização de fontes históricas em sala pode contribuir para a atualização do conhecimento escolar, servindo para quebrar mitos e estereótipos ainda presentes sobre o nosso passado colonial.

\section{O projeto "Sala de Aula": o ensino da HISTÓRIA LUSO-BRASILEIRA POR MEIO DE FONTES}

Como afirmou Eric Hobsbawm, a história exerce papel fundamental na construção de uma nação, uma vez que por meio dela é que se institui um passado comum, compartilhado por todos os membros de uma sociedade (Hobsbawm, 1998, p.22-35). A escrita da história, nesse sentido, tem importância crucial na construção de um passado; por meio da reprodução do 
conhecimento serão formadas as futuras gerações, as quais levarão adiante a noção de pertencimento.

Com relação à história brasileira, apesar de a emancipação política ter acontecido em 1822, o que existia, nas primeiras décadas do Império independente, era um conjunto de províncias dispersas, com identidades diferentes, unidas apenas por uma língua em comum e por um Estado monárquico, centralizado no Rio de Janeiro. Era necessário, nesses anos iniciais, consolidar o Estado nacional e, para isso, construir um passado que desse unidade às antigas colônias portuguesas, anteriormente unificadas por Lisboa (Jancsó; Pimenta, 2000).

A historiografia que debate tal tema demonstra que algumas instituições foram fundamentais na construção de uma unidade imperial: o Colégio Pedro II, instituído em 1837 e que tinha por objetivo formar os filhos da elite imperial; o Arquivo Público do Império e o Instituto Histórico e Geográfico Brasileiro (IHGB), ambos criados em 1838. Coube ao IHGB a função de elaborar um projeto de história nacional, sendo o Arquivo Público apenas uma instituição com finalidades burocráticas de recolhimento de documentos oficiais da administração central e dos governos provinciais. Foi apenas no período republicano, "quando o governo promoveu substanciais alterações na sua estrutura, em 1911, alterando-lhe inclusive a denominação para Arquivo Nacional", que o Arquivo Público passou a ser pensado como lugar de memória (Guimarães, 2002).

A história redigida pelo IHGB estava essencialmente comprometida "com o desvendamento do processo da nação" (Guimarães, 1988, p.6). A ideia era produzir um discurso único sobre o Brasil, homogeneizando partes dispersas e atribuindo a cada uma das três raças (branca, negra e índia) o seu papel naquela sociedade. Nesse projeto, a identidade nacional brasileira foi percebida como herança da colonização europeia. A expressão maior dessa escrita da história pode ser vista na obra História Geral do Brasil (1854-1857), de Francisco Adolfo de Varnhagen.

Representante de um pensamento dominante no século XIX, essa obra adquiriu importância por representar uma perspectiva de seu tempo, vinculada a um projeto político de Estado. Cumpriu, igualmente, papel de construir um passado que atendia ao interesse das elites imperiais. Na visão de Varnhagen, a História do Brasil começa com a chegada dos portugueses à América, defendendo a interferência do colonizador na civilização dos índios e na ordenação 
do território. Nos capítulos dedicados aos indígenas, sua argumentação tem por objetivo demonstrar que o futuro do Brasil não poderia ter, nesse passado, a sua raiz. Sua História Geral do Brasil é uma história político-administrativa, repleta de fatos, nomes e datas (Reis, 2002, p.23-50).

Apesar de terem se passado mais de 150 anos da publicação dessa obra, e apesar de uma produção cada vez mais frequente apontando a necessidade de avanços nos conteúdos ministrados em sala de aula, ainda hoje, no ensino de História, encontramos algumas permanências dessa produção historiográfica do século XIX. Exemplos, nesse sentido, podem ser percebidos na própria forma como o conhecimento é estruturado, a partir de uma visão eurocêntrica. Se analisarmos a organização dos conteúdos ministrados no ensino fundamental e médio, perceberemos que a História do Brasil é oferecida a partir do $7^{\circ}$ ano e inserida no contexto da História europeia.

De igual maneira, enfatiza-se a ação colonizadora portuguesa, estudada em seus âmbitos administrativo, econômico e religioso. Sobre os povos dominados, como os índios, por exemplo, frequentemente dedica-se a eles um capítulo nos livros didáticos, no qual se apresenta um panorama geral. $\mathrm{O}$ breve espaço disponível não permite apresentar sua diversidade histórica e cultural. E apesar dos avanços atuais nas pesquisas sobre esses povos, compostos por diversas etnias e tribos, mitos e estereótipos presentes na memória coletiva continuam sendo reproduzidos na sala de aula.

Uma reprodução que, por vezes, baseia-se na utilização de determinados livros didáticos, escolhidos sem maior rigor em relação a sua constituição teórica e apresentação de conteúdos. No trabalho de seleção dos livros didáticos, deve-se atentar para o fato de que, se eles facilitam a prática pedagógica, também são portadores de uma ideologia e de uma cultura dominante, que quer se impor sobre as demais (Bittencourt, 2004, p.72). Objeto de inúmeras polêmicas, estudos atuais têm contribuído para relativizar o papel de "vilão da história" dos livros didáticos, fortemente defendida nos anos 1980, indicando o quanto alguns autores têm buscado incorporar em suas páginas novas dimensões da historiografia, ligadas às questões sociais, às relações de gênero, à chamada "História vista de baixo" e à História Integrada, por exemplo (Monteiro, 2009).

O livro didático pode ser utilizado como objeto único de seleção de conteúdos, ou como um norteador, associado a outras fontes e mídias, tais como 
documentos históricos, filmes e músicas, assumindo, assim, o papel de constituir mais um item na pluralidade da sala de aula. Quando ressaltamos o aspecto da pluralidade de recursos que hoje se coloca para as atividades em sala de aula, para além de reconhecermos as mudanças que estão se realizando no campo do ensino de História, defendemos o protagonismo do professor, em sua prática pedagógica, como o profissional que contribui cotidianamente para a implementação de escolhas e caminhos para a construção do conhecimento histórico, mesmo sem ter, muitas vezes, o apoio da escola e/ou, dependendo de seus posicionamentos, também dos pais ou responsáveis pelos alunos.

$\mathrm{Na}$ construção de sua prática pedagógica, a atualização em relação à teoria e às práticas do ensino de História, que antes dependiam exclusivamente de cursos e/ou da compra ou empréstimo de material especializado, cada vez mais se coloca por meio de textos e projetos disponíveis na internet. Mas, conforme observa Flávia Caimi, o fato de a sociedade atual ser marcada pela cultura digital requer outras formas de aprendizado, distintas da que tradicionalmente conhecemos. Dessa forma, o grande desafio que se coloca aos educadores é a criação de respostas compatíveis com as mudanças e novas demandas educativas e sociais, tomando os valores da nova geração como fonte de inspiração para a sua prática (Caimi, 2014, p.165-169). Segundo Silva e Freitas, é preciso que os educadores assumam "novos papéis diante das novidades impostas pela sociedade contemporânea", utilizando os recursos em sua prática docente:

A sociedade contemporânea está condicionada pelas tecnologias e mídias que geram novas sensibilidades humanas e modificam a maneira de organizar muitas atividades. Existe a necessidade de a educação estar atenta a essas mudanças e levar para o interior da escola um trabalho que contemple a inter-relação comunicação/educação, ou seja, a educomunicação. (Silva; Freitas, 2015)

Nesse escopo é que ressaltamos a importância do projeto "Sala de Aula”, hospedado no site "O Arquivo Nacional e a História Luso-Brasileira". Seguindo o modelo de outros países, como Inglaterra, Estados Unidos e França, que buscaram adequação da linguagem documental à prática escolar, o projeto visa trazer a público um conjunto de documentos sobre a época da colonização portuguesa na América, os quais podem ser utilizados pelos professores: 
A inscrição ativa na área pedagógica tornou-se um aspecto fundamental da atividade de pesquisa e de difusão do acervo da instituição, fornecendo material para uso nas escolas e introduzindo novos textos - documentos de época a serem analisados -, identificando, desse modo, a disciplina da história como um campo de conhecimento em construção. (Heynemann et al., 2005, p.176)

Em artigo publicado sobre o projeto, o grupo idealizador argumenta que o "Sala de Aula" teve por objetivo "atender à demanda da rede de ensino pública e privada que procura o Arquivo Nacional como parte das atividades extraclasse, bem como o interesse institucional no desenvolvimento dessa linha, dentro da área de pesquisa e difusão cultural” (Heynemann et al., 2005, p.177).

O projeto elaborado a partir de 2002 visa à difusão do acervo da instituição referente ao período da colonização portuguesa na América, servindo ainda como um espaço de divulgação de informações acadêmicas, lançamentos editoriais, seminários, congressos e projetos. Além do "Sala de Aula", o site conta com uma base de dados, o Roteiro de Fontes do Arquivo Nacional para a História luso-brasileira, por meio do qual é possível consultar a "parcela do acervo institucional compreendida no período entre o final do século XVI e as duas primeiras décadas do século XIX", composta por cerca de 170 fundos ou coleções, "de proveniência pública ou privada, produzidos, principalmente, pela administração central e por tribunais e câmaras, em Portugal ou em suas colônias, em sua maior parte na colônia americana” (Heynemann et al., 2005, p.173).

O Roteiro de Fontes é o fundamento de todo o site do Arquivo Nacional e a História Luso-Brasileira. A consulta realiza-se por meio de descritores, onomásticos, toponímicos e temáticos, e por datas-limites escolhidas pelos usuários. Voltado para historiadores e interessados na pesquisa histórica, facilitou substancialmente o acesso à documentação colonial do Arquivo Nacional, uma vez que evidenciou

diversos aspectos da documentação que não eram identificados pelos instrumentos de pesquisa, além de criar uma outra dinâmica de consulta, comunicando documentos de diferentes proveniências entre si. O Roteiro permite, assim, a seleção de temas como arte, cidades, domínio holandês, comércio de escravos, família, festas religiosas, história natural, índios, manufaturas, mineração, Portugal - invasão napoleônica, habitação, produtos tropicais, quilombos, pau-brasil, entre tantos outros. Também as espécies documentais são variadas, como 
cartas régias, alvarás, inventários post-mortem, processos crimes, memórias etc. Esse amplo espectro temático oferecido pela base de dados subsidia toda a atividade de pesquisa envolvida no site. (Heynemann et al., 2005, p.173)

Se o Roteiro de Fontes exerce função acadêmica, o "Sala de Aula", por sua vez, pode ser visto como um elo entre essa produção e o ensino de História. $\mathrm{O}$ projeto foi estruturado, inicialmente, a partir de quatro dossiês temáticos: Expansão Portuguesa; Brasil; Portugal e Império Luso-Brasileiro, os quais se encontram divididos em subtemas. Em 2008, com a comemoração dos 200 anos da chegada da Corte portuguesa ao Rio de Janeiro, acrescentou-se mais um dossiê: "A Corte no Brasil", que tratou do momento específico da permanência do príncipe regente Dom João na América (1808-1821). Na relação seguinte, elencamos os subtemas por eixos temáticos:

\section{Subtemas POR EIXos Temáticos}

\section{Expansão Portuguesa}

- Oriente

- Congo-Angola

- Moçambique

- Ilhas Atlânticas

\section{Brasil}

- Administração colonial

- Irmandades

- Jardins botânicos

- Cidades

- Companhia de Jesus

- Índios

- Festas coloniais

- Vida privada

- História natural

- Quilombos e revoltas de escravos

- Pau-brasil: do estanco à extinção

- Marquês do Lavradio 
- Indumentária colonial

- Conjuração em Minas Gerais

- Questão Cisplatina

- Sociedade do Açúcar

- Alimentação na América portuguesa

- Grão-Pará e Maranhão sob a política ilustrada

- Impostos, contrabando e revoltas

- Nossa Senhora dos Remédios de Parati

- Ouro e diamantes na colônia americana

- Mulatos na sociedade colonial

- Saúde e higiene pública na ordem colonial e joanina

- Prisões, presigangas e cadeias na colônia

- Pesca da baleia na colônia

- Penalidades aos escravizados: 1808-1821

\section{Portugal}

- Ideias políticas

- Cidades

- Real Academia das Ciências de Lisboa

- Política externa no mundo árabe e islâmico

\section{Império Luso-Brasileiro}

- Caiena

- Judeus e cristãos-novos

- Tráfico de escravos

- Bibliotecas, imprensa e censura

- Ciganos

- Limites e fronteiras

- Franceses na colônia

- Geração de 1790: Bonifácio, Cairu e Souza Coutinho

- Colônia de Sacramento

- Viagens e expedições

- Repressão ao tráfico de escravos

- Órfãos e expostos no Império Luso-Brasileiro

- Diplomacia e política externa na América joanina 
- Ordens Terceiras

- Estrangeiros e Guerra: um ministério na corte joanina

\section{A Corte no Brasil}

- Polícia da Corte

- Casa Real

- Práticas Médicas

- Abertura dos Portos

- Vida artística e urbana

- Ensino e Ilustração

- Rio de Janeiro: uma nova ordem na cidade

- Tempo das fábricas

- Invasões francesas

- Confederação do Equador

- Marquês de Barbacena

- Independência do Brasil

- Escravidão na Marinha

- Revolução de 1817

Fonte: Disponível em: http://www.historiacolonial.arquivonacional.gov.br/; Acesso em: 20 dez. 2016.

No total, são cerca de sessenta subtemas que abrangem o período da História colonial portuguesa, indo até a Independência do Brasil. Digna de destaque é a diversidade de assuntos que podem ser trabalhados a partir desse material, que contemplam, de certo modo, boa parte dos eixos temáticos estabelecidos pelos PCNs.

As páginas relativas aos subtemas são compostas por quatro partes, a saber: o "comentário", breve texto redigido por um especialista, por meio do qual contextualiza o assunto analisado; as "sugestões bibliográficas", cerca de dez livros, para a hipótese de se querer aprofundar as leituras; as "ementas", pequenos resumos dos documentos do Arquivo Nacional sobre o tema em destaque; e o "Sala de Aula". O professor que se utiliza de um subtema do site conta, desse modo, com toda uma estrutura de conhecimento para o seu trabalho com os alunos. 


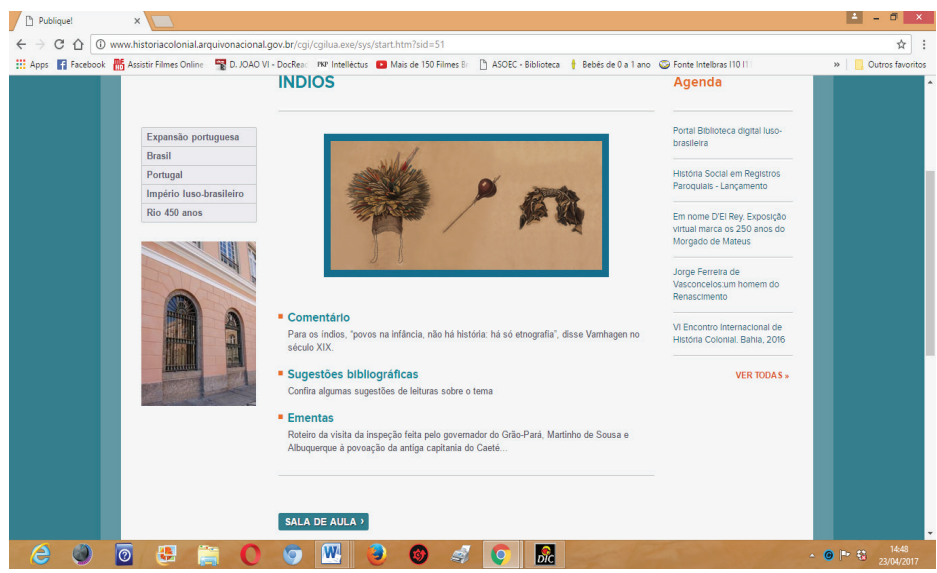

Figura 1 - Subtema "Índios" no site Arquivo Nacional e a História Luso-Brasileira, com as possibilidades de trabalho a partir dos Comentários, Sugestões Bibliográficas e Ementas de documentos.

O "Sala de Aula”, por sua vez, conta com uma página específica, composta por três documentos transcritos na íntegra ou em parte, com a ortografia atualizada. Cada uma dessas fontes é acompanhada de verbetes explicativos, cujo objetivo é fornecer, ao professor, caminhos que podem ajudá-lo a explorar os documentos apresentados. Em muitos casos, disponibiliza-se o manuscrito, que se torna igualmente um instrumento de trabalho para o docente.

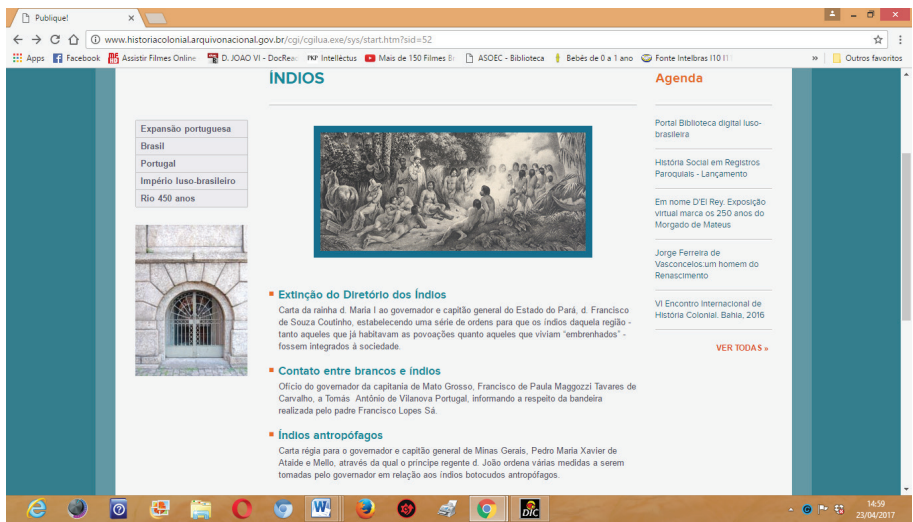

Figura 2 - Sessão "Sala de Aula", com a temática "Índios" e os documentos "Extinção do Diretório dos Índios", "Contato entre brancos e Índios" e "Índios Antropófagos" transcritos. 
Inúmeras são as possibilidades que se abrem para o professor com a utilização desse material. Como destacou o grupo idealizador em momento anterior:

para trabalhar um período histórico, por exemplo, o professor pode optar por não datar o documento. Dessa forma, poderá convidar os alunos a se perguntarem a que acontecimentos ou personagens se refere o referido texto; ou ainda, a que outros momentos históricos liga-se este tema. Também poderá abordar o caráter oficial ou não do documento, mostrando os variados tipos de fontes e atores sociais existentes. Uma outra linha a ser seguida diz respeito à análise do vocabulário e conceitos de época. Esse exercício pode ser realizado através da comparação com os termos atuais, enfatizando a diferença dos seus significados sociais, culturais e políticos. (Heynemann et al., 2005, p.178)

O projeto, a nosso ver, é uma ferramenta relevante para ajudar o professor, a partir do uso de fontes históricas, a quebrar certos mitos e estereótipos sobre o período colonial da História brasileira - tais como a preguiça dos índios, a ausência de contestações à ordem colonial, a passividade dos escravos e a subserviência das mulheres - frequentemente repetidos em livros, filmes e novelas, fornecendo elementos que demonstram a riqueza do nosso passado. Entretanto, no trabalho com esse material, o docente precisa estar atento e explicar aos alunos que se trata de um tipo específico de documento: fontes manuscritas, por meio das quais se apresentam apenas algumas marcas do passado, que podem ser complementadas com a análise de outros tipos de fontes, como jornais, pinturas, telas e músicas. Isso porque, como argumentou Circe Bittencourt,

Para que o documento se transforme em material didático significativo e facilitador da compreensão de acontecimentos vividos por diferentes sujeitos em diferentes situações, é importante haver sensibilidade ao sentido que lhe conferimos enquanto registro do passado. Nessa condição, convém aos alunos perceberem que tais registros e marcas do passado são os mais diversos e encontram-se por toda a parte: em livros, revistas, quadros, músicas, filmes e fotografias. (Bittencourt, 2005, p.331)

Os livros didáticos, se muitas vezes são instrumentos facilitadores no cotidiano escolar, nos dias atuais não dão conta da atualização do conhecimento. 
Como afirma Circe Bittencourt (2004), não devem ser os únicos instrumentos no processo do ensino-aprendizagem. É preciso que o docente busque outros tipos de recursos, e o uso de uma ferramenta disponibilizada na internet cumpre tal função. Além do mais, a riqueza de temas, proporcionada pelo site em questão, permite ao professor construir com o aluno o conhecimento histórico. Ao atuar com o professor, o discente exerce uma função de sujeito do processo educativo, atingindo, assim, um importante pressuposto indicado nos PCNs.

Uma proposta metodológica que vise transformar o aluno em sujeito, a partir do uso de documentos históricos, implica trazer a problematização, o questionamento, como algo importante na produção do conhecimento, como destacou Selva Fonseca:

A proposta de metodologia do ensino de História, que valoriza a problematização, concebe alunos e professores como sujeitos que produzem história e conhecimento em sala de aula. Logo, são pessoas, sujeitos históricos que cotidianamente atuam, transformam, lutam e resistem nos diversos espaços de vivência: em casa, no trabalho, na escola. (Fonseca, S., apud Pereira Neto, 2001, p.152)

Conhecer a nossa própria história é fundamental para que possamos construir uma sociedade mais justa e igualitária. Desse modo, o professor, em sua atividade em sala de aula, deve ter como meta contribuir para a quebra de mitos e paradigmas ainda reproduzidos no cotidiano escolar. E o uso de documentos históricos pode ser visto como um recurso pedagógico de extrema importância nessa tarefa.

\section{REFERÊNCIAS}

BITTENCOURT, Circe Maria F. (Org.) O saber histórico na sala de aula. 9.ed. São Paulo: Contexto, 2004.

. Ensino de História: fundamentos e métodos. São Paulo: Cortez, 2005.

BRASIL. Ministério da Educação. Parâmetros Curriculares Nacionais: História. Brasília, 1999.

BUENO, Paula A. R.; DALLA COSTA, Rosa Maria C.; BUENO, Roberto Eduardo. A educomunicação na educação musical e seu impacto na cultura escolar. Educação e Pesquisa, São Paulo, v.39, n.2, p.493-507, abr./jun. 2013. Disponível em: http:// www.revistas.usp.br/ep/article/view/58631/61701; Acesso em: 15 abr. 2017. 
CAIMI, Flávia Eloisa. Fontes históricas na sala de aula: uma possibilidade de produção de conhecimento histórico escolar? Revista Anos 90, Porto Alegre, v.15, n.28, p.129-150, dez. 2008. Disponível em: http://www.seer.ufrgs.br/index.php/anos90/ article/view/7963; Acesso em: 20 fev. 2017.

- Geração Homo Zappiens na escola: os novos suportes de informação e a aprendizagem histórica. In: MAGALHÃES, Marcelo (et al.) Ensino de história: usos do passado, memória e mídia. Rio de Janeiro: Ed. FGV, 2014. p.165-183.

FONSECA, Selva Guimarães. Didática e prática de ensino de história: experiência, reflexões e aprendizados. São Paulo: Papirus, 2003.

FONSECA, Thais Nívia de L. e. História \& Ensino de História. Belo Horizonte: Autêntica, 2003.

GUIMARÃES, Lúcia. Arquivo Público do Império. In: VAINFAS, Ronaldo (Org.) História do Brasil Imperial. Rio de Janeiro: Objetiva, 2002.

GUIMARÃES, Manoel Luís S. Nação e Civilização nos Trópicos. O Instituto Histórico e Geográfico Brasileiro e o Projeto de uma História Nacional. Revista de Estudos Históricos, Rio de Janeiro: FGV, n.1, p.5-27, 1988.

HALBWACHS, Maurice. A memória coletiva. São Paulo: Vértice, 1990.

HEYNEMANN, Cláudia B.; ISHAQ, Vivien; DUARTE, Elaine Cristina F.; ZAMPA, Vivian. O Arquivo Nacional vai às escolas. Acervo, Rio de Janeiro, v.18, n.1-2, p.171-182, jan./dez. 2005. Disponível em: http://revista.arquivonacional.gov.br/ index.php/revistaacervo/article/view/192/192; Acesso em: 1 fev. 2017.

HOBSBAWM, Eric. Sobre a História. São Paulo: Companhia das Letras, 1998.

JANCSÓ, István; PIMENTA, João Paulo G. Peças de um mosaico (ou apontamentos para o estudo da emergência da identidade nacional brasileira). In: MOTA, Carlos Guilherme (Org.) Viagem incompleta: a experiência Brasileira (1500-2000). Formação histórias. São Paulo: Ed. Senac São Paulo, 2000. p.127-175.

LINDEMEYER, Maurício R. O indígena no livro didático: memórias e identidades nas terras do Pará. Anais do SILEL, Uberlândia: Edufu, v.3, n.1, p.1-10, 2013. Disponível em: http://www.ileel.ufu.br/anaisdosilel/wp-content/uploads/2014/04/ silel2013_695.pdf; Acesso em: 10 jun. 2017.

MATHIAS, Carlos Leonardo K. O ensino de História no Brasil: contextualização e abordagem historiográfica. História Unisinos, São Leopoldo, v.15, n.1, p.40-49, jan./abr. 2011. Disponível em: http://revistas.unisinos.br/index.php/historia/article/viewFile/959/163; Acesso em: 5 mar. 2017.

MONTEIRO, Ana Maria. Professores e livros didáticos: narrativas e leituras no ensino de História. In: ROCHA, Helenice; REZNIK, Luís; MAGALHÃES, Marcelo de S. (Org.) A História na escola: autores, livros e leituras. Rio de Janeiro: Ed. FGV, 2009. p.177-199. 
NADAI, Elza. O ensino de História no Brasil: trajetória e perspectiva. Revista Brasileira de História, n.25/6. São Paulo: Anpuh, n.2/6, p.143-162, 1993. Disponível em: www.anpuh.org/arquivo/download?ID_ARQUIVO=30596; Acesso em: 31 jan. 2017.

PEREIRA, Nilton Mullet; SEFFNER, Fernando. O que pode o ensino de História? Sobre o uso de fontes na sala de aula? Revista Anos 90, Porto Alegre, v.15, n.28, p.113-128, dez. 2008. Disponível em: http://www.seer.ufrgs.br/index.php/anos90/ article/view/7963; Acesso em: 20 fev. 2017.

PEREIRA NETO, André de Faria. O uso de documentos escritos no Ensino de História. Premissas e bases para uma didática construtivista. História \& Ensino, Londrina, v.7, p.143-165, out. 2001. Disponível em: http://www.uel.br/revistas/uel/ index.php/histensino/article/view/12314; Acesso em: 11 fev. 2017.

PINSKY, Carla Bassanezi. Fontes Históricas. São Paulo: Contexto, 2005.

PINSKY, Jaime. O ensino de história e a criação do fato. São Paulo: Contexto, 1988.

REIS, José Carlos. As identidades do Brasil de Varnhagen a FHC. Rio de Janeiro: Ed. FGV, 2002.

SILVA, Aline N.; FREITAS, Maria do Carmo D. O uso do audiovisual nas aulas de história de escolas particulares de Curitiba segundo a perspectiva dos professores. Percurso, Curitiba, v.15, n.2, 2015. Disponível em: http://revista.unicuritiba.edu. br/index.php/percurso/article/view/1142/769; Acesso em: 11 fev. 2017.

SILVA, Kalina V.; SILVA, Maciel Henrique. Dicionário de conceitos históricos. 2.ed. São Paulo: Contexto, 2009.

Artigo recebido em 3 de maio de 2017. Aprovado em 3 de julho de 2017. 